\title{
Characterization Of Sansivieria Trifasciata's Mechanical Properties As Filler In Fiberglass Manufacture
}

\author{
Kartika Sari ${ }^{1}$, Sunardi ${ }^{2}$ \\ ${ }^{1,2)}$ Lecturer Physics Study Program, Faculty of Science and Engineering, \\ Jenderal Soedirman University (UNSOED)
}

\begin{abstract}
The fiberglass technology is made from polycarbonate production processthat has disadvantage of expensive, environmentally unfriendly and not able to absorb some heat intensity. Though fiberglass materials can now be based on organic materials that are environmentally friendly and easy to obtain. One of the organic leaf comes from nature is Sansivieria Trifasciata. Characterization of Sansivieria Trifasciata's mechanical properties with matrix of epoxy resin as fiberglass conducted to determine compressive strength, tensile strength and impact. Variation of the composition of fibers and the matrix is a ratio of $0 \%: 100 \%, 20 \%: 80 \%, 35 \%: 65 \%$ and $50 \%: 50 \%$, while the variation in thickness is $2 \mathrm{~mm}$ and 3 $\mathrm{mm}$. Based on the analysis of compressive strength, tensile strength and impact test concluded that the fiber-based composite materials Sansivieria Trifasciata as a filler and epoxy resin as a matrix that is generated can be used as an alternative to the manufacture of fiberglass because it has a compressive strength, impact and tensile strength greater than the thickness of the thinner fiberglass manufacturer. In other word, by Sansivieria Trifasciata, we are going to green scientific research.

Keywords: composites, Sansivieria Trifasciata, compressive strength, tensile strength, impact fiberglass.
\end{abstract}

\section{INTRODUCTION}

Material resulting from the processing of leaf fibers of Sansivieria Trifasciata (Picture 1.) can be applied to the fiberglass. An alternative material used to produce fiberglass should have a compressive strength and tensile one. Organic composite is the right type of material to be used as an alternative to fiberglass. This is due to fiberglass manufacturers that can not be environmentally friendly and cost of the production process requires a fairly high. So it requires a composite material that is environmentally friendly and cheaper production costs.

Environmentally friendly composite materials are usually based on organic fibers that can be obtained around us, in anywhere. The resulting composite material called organic. An organic composite material composed of a combination of two or more elements that have different properties from the properties of each constituent element ${ }^{[1,2]}$. Constituent base material is a composite of organic material. Material properties of the merger is expected to complement the weaknesses that exist in each of its constituent material. The properties that can be updated include strength, stiffness and toughness ${ }^{[3]}$.

In general, a composite material consisting of two elements, namely filler (filler) and binder (matrix) ${ }^{[4.5]}$. Filler serves to add strength, rigidity and plasticity of materials, while the matrix serves to protect the amplifier and the force transfer and temperature ${ }^{[7,8]}$. Based on his type of matrix, composite materials can be grouped into four, the metal matrix composites, polymer matrix composites, ceramic matrix composites and composites with carbon matrix. The matrix is a polymer commonly used for its treatment more easily than other materials that require its own way.

The studies have been carried out aimed at improving the function of the Sansivieria Trifasciata, by utilizing the fiber as filler composite. Research on the composite has been carried out by Ludi Hartanto ${ }^{[9]}$ with helm fiber filler, the resulting conclusion that the influence of fiber volume fraction strongly stressed.

Based on the description, we conducted a study of composite materials with fiber filler leaves Sansivieria Trifasciata with an epoxy resin matrix. The resulting composites were then tested the mechanical properties (mechnical properties) to analyze the effect of variations in thickness and composition of the solid compressive $\mathrm{e}^{[10,11]}$. Test results are then compared with test results fiber glass, so it is known that the resulting composite material can be applied as an alternative to produce fiber glass or not.

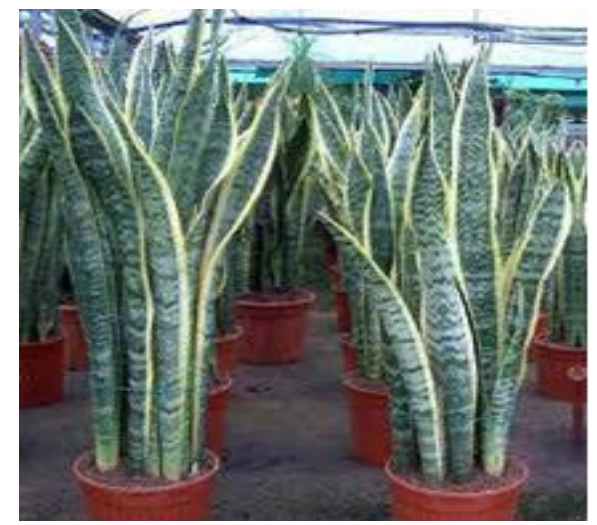

Picture 1. Leaf of Sansivieria Trifasciata

\section{METHODS}

\section{a. The Preparing Composite Phase}

The preparing process begins with the manufacture of fiber composites. Once the desired fiber is obtained, then make a composite by mixing epoxy resin and epoxy hardener, the mixture was poured into a mold and arranged along the fiber with the fiber and matrix ratio 0\%: $100 \%, 20 \%$ : $80 \%, 35 \%$ : $65 \%$ and $50 \%$ : $50 \%$ had a thickness of $2 \mathrm{~mm}$ and $3 \mathrm{~mm}$. 


\section{b. The Testing Phase}

At this stage of the composite have been made and tested characteristics. Testing characteristics of the mechanical properties of composite compressive strength, tensile strength and impact test for determining Sansivieria Trifasciata's mechanical properties from material composite resulted.

\section{c. The Analysis Phase}

Based on the test characteristics of the resulting composite data obtained tensile strength and compressive strength. At this stage of analysis compressive strength and tensile strength of the resulting composite. The results are then compared with the results of testing compressive strength and tensile strength of fiberglass.

\section{RESULTS AND DISCUSSION}

\section{a. Analysis of Compresissive Strength}

Obtained from the test maximum force required to break the composite. The force obtained is then processed by the equation:

$$
\sigma=\frac{3 F l}{2 b a^{2}}
$$

with $\mathrm{F}$ is the maximum force required to break the composite $(\mathrm{N}), 1$ is the length of the composite $(\mathrm{m}), \mathrm{b}$ is the width of the composite $(\mathrm{m})$ and $\mathrm{a}$ is the composite thickness (m) that generated the data in Table 1. as follows:

\section{Table 1. Compressive Strength Measurement Results}

\begin{tabular}{|l|l|l|l|}
\hline $\begin{array}{l}\text { Specime } \\
\mathrm{n} \\
\text { thickness }\end{array}$ & $\begin{array}{l}\text { Ratio } \\
\text { volume } \\
\text { fiber and } \\
\text { matrix }\end{array}$ & $\begin{array}{l}\text { Force } \\
(N)\end{array}$ & $\begin{array}{l}\text { Compressi } \\
\text { ve Strength } \\
(\mathrm{MPa})\end{array}$ \\
\hline \multirow{4}{*}{$2 \mathrm{~mm}$} & $0 \%: 100 \%$ & 13 & 47,78 \\
\cline { 2 - 4 } & $20 \%: 80 \%$ & 22 & 80,85 \\
\cline { 2 - 4 } & $35 \%: 65 \%$ & 25 & 91,88 \\
\cline { 2 - 4 } & $50 \%: 50 \%$ & 35 & 128,63 \\
\hline \multirow{5}{*}{$3 \mathrm{~mm}$} & $0 \%: 100 \%$ & 33 & 53,90 \\
\cline { 2 - 4 } & $20 \%: 80 \%$ & 35 & 57,17 \\
\cline { 2 - 4 } & $35 \%: 65 \%$ & 44 & 71,87 \\
\cline { 2 - 4 } & $50 \%: 50 \%$ & 63 & 102,90 \\
\hline
\end{tabular}

Copressive Strength of composites with an average thickness of $2 \mathrm{~mm}$ and $3 \mathrm{~mm}$ as shown graphically in Figure 1.

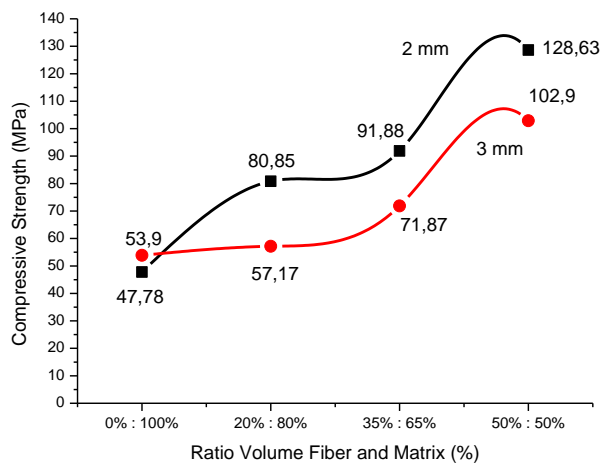

Figure 1. Compressive strength of Sansivieria Trifasciata's composite for thickness of $2 \mathrm{~mm}$ and $3 \mathrm{~mm}$

The highest compressive strength is represented a thickness of $2 \mathrm{~mm}$ is $128.63 \mathrm{MPa}$ with a ratio of $50 \%$ : $50 \%$, while the lowest are in the ratio of $0 \%$ : $100 \%$ which is equal to $47.78 \mathrm{MPa}$. And the highest compressive strength for a thickness of $3 \mathrm{~mm}$ is 102.9 $\mathrm{MPa}$ is obtained at a ratio of $50 \%: 50 \%$, while the lowest are in the ratio of $0 \%: 100 \%$ which amounted to 53.9 $\mathrm{MPa}$.

From Figure 1. can be concluded that the compressive strength of composites is influenced by variations in composition and thickness of the composite is used. The larger the volume fraction of fibers that are used the greater the resulting compressive strength. This is consistent with fibers as a function of the filler increases the stiffness and strength of the composites ${ }^{[7,8]}$. The amount of fiber that the more lead weight received by each of the smaller fibers. The amount of fiber that many also cause the matrix used had a greater influence of the fiber so that the composite is not prone to cracking. Based on ASTM D 790-02 ${ }^{[14]}$ The compressive strength is proportional to the magnitude of the force and inversely proportional to the square of its thickness. An increase in the style of tap test results of composite thickness of $3 \mathrm{~mm}$ have not been able to increase the value of a strong compressive. In order to enhance the strong compressive, then the force generated must be two-fold greater for each increase of thickness. As influenced by the type of filler used. Filler used in this study is the Sansivieria Trifasciata's fiber. The fiber has a very small size so that although the number and thickness of the composite is increased, the increase in the force generated is not significant.

\section{b. Analysis of Tensile Strength}

Obtained from the test maximum force required to break the composite. Tensile strength obtained was processed by the equation:

$$
\sigma=\frac{F}{A}
$$

with $\mathrm{F}$ is the maximum force required to break the composite $(\mathrm{N})$, A is a composite area $\left(\mathrm{m}^{2}\right)$ that generated the data in Table 1. as follows: 
Table 2. Tensile Strength Measurement Results

\begin{tabular}{|l|l|l|l|}
\hline $\begin{array}{l}\text { Specime } \\
\mathrm{n} \\
\text { thickness }\end{array}$ & $\begin{array}{l}\text { Ratio } \\
\text { Volume } \\
\text { Serat and } \\
\text { Matrix }\end{array}$ & $F(N)$ & $\begin{array}{l}\text { Tensile } \\
\text { Strengt } \\
\mathrm{h} \\
(\mathrm{MPa})\end{array}$ \\
\hline \multirow{5}{*}{$2 \mathrm{~mm}$} & $0 \%: 100 \%$ & 1,15 & 33,8 \\
\cline { 2 - 4 } & $20 \%: 80 \%$ & 1,45 & 32,5 \\
\cline { 2 - 4 } & $35 \%: 65 \%$ & 1,78 & 36,5 \\
\cline { 2 - 4 } & $50 \%: 50 \%$ & 2,19 & 39,4 \\
\hline \multirow{5}{*}{$3 \mathrm{~mm}$} & $0 \%: 100 \%$ & 1,20 & 47,6 \\
\cline { 2 - 4 } & $20 \%: 80 \%$ & 2,47 & 78,1 \\
\cline { 2 - 4 } & $35 \%: 65 \%$ & 2,88 & 89,6 \\
\cline { 2 - 4 } & $50 \%: 50 \%$ & 3,42 & 77,5 \\
\hline
\end{tabular}

Composite tensile strength with an average thickness of $2 \mathrm{~mm}$ and $3 \mathrm{~mm}$ is displayed in graphical form as shown in Figure 2.

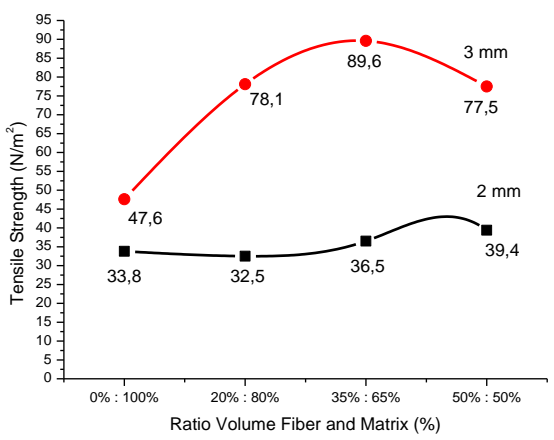

Figure 2. Tensile Strength the composite thickness of $2 \mathrm{~mm}$ and $3 \mathrm{~mm}$

In Figure 2. Stating the highest tensile strength of 39.4 $\mathrm{MPa}$ is obtained at a ratio of $50 \%: 50 \%$, while the lowest at a ratio of $20 \%: 80 \%$ of $32.5 \mathrm{MPa}(2 \mathrm{~mm})$. The highest tensile strength of $89.6 \mathrm{MPa}$ is obtained at a ratio of $35 \%$ : $65 \%$, while the lowest at a ratio of $0 \%: 100 \%$ at 47.6 $\mathrm{MPa}(3 \mathrm{~mm})$.

Based on Figure 2., we can be conclud that the composite tensile strength is influenced by variations in composition and thickness of the composite is used. To a thickness of $2 \mathrm{~mm}$ and $3 \mathrm{~mm}$, the effect of fiber volume ratio of the matrix is initially increased and then decreased, it is because there are many pores or voids between the fibers and matrix in the composites produced, resulting in the composite is easy to break when pulled. This is due at the time of the composite is printed, the composition of leaf fibers of the tongue-inlaw does not occupy space, and so the material is easy to break when pulled. Based on ASTM D 638-03 the tensile strength is proportional to the magnitude of the force and inversely proportional to the area of the material, so it can be determined modulus of elasticity of the resulting material. As influenced by the type of filler used.

\section{c. Analysis of Impact}

Obtained from the test maximum force required to break the composite. Impact obtained was processed by the equation:

$$
N I=\frac{E_{\text {Ab sorpstion }}}{A}
$$

with NI is impact value $\left(\mathrm{kJ} / \mathrm{m}^{2}\right), \mathrm{E}_{\mathrm{Absorption}}$ is the maximum energy absorption the composite until deformation $(\mathrm{J})$, A is a composite area $\left(\mathrm{m}^{2}\right)$ that generated the data in Table 3. as follows:

Table 3. Impact Measurement Result

\begin{tabular}{|l|l|l|l|}
\hline \multirow{2}{*}{$\begin{array}{l}\text { Specime } \\
\mathrm{n} \\
\text { thickness }\end{array}$} & $\begin{array}{l}\text { Ratio } \\
\text { Volume } \\
\text { Fiber and } \\
\text { Matrix }\end{array}$ & $\begin{array}{l}\text { Energy } \\
(\mathrm{J})\end{array}$ & $\begin{array}{l}\text { Impact } \\
\left(\mathrm{kJ} / \mathrm{m}^{2}\right)\end{array}$ \\
\hline \multirow{4}{*}{$2 \mathrm{~mm}$} & $0 \%: 100 \%$ & 0,033 & 3,25 \\
\cline { 2 - 4 } & $20 \%: 80 \%$ & 0,091 & 6,10 \\
\cline { 2 - 4 } & $35 \%: 65 \%$ & 0,158 & 9,35 \\
\cline { 2 - 4 } & $50 \%: 50 \%$ & 0,224 & 12,61 \\
\hline \multirow{5}{*}{$3 \mathrm{~mm}$} & $0 \%: 100 \%$ & 0,091 & 4,07 \\
\cline { 2 - 4 } & $20 \%: 80 \%$ & 0,158 & 6,24 \\
\cline { 2 - 4 } & $35 \%: 65 \%$ & 0,291 & 10,57 \\
\cline { 2 - 4 } & $50 \%: 50 \%$ & 0,515 & 20,34 \\
\hline
\end{tabular}

Impact of composites with an average thickness of $2 \mathrm{~mm}$ as shown graphically in Figure 3.

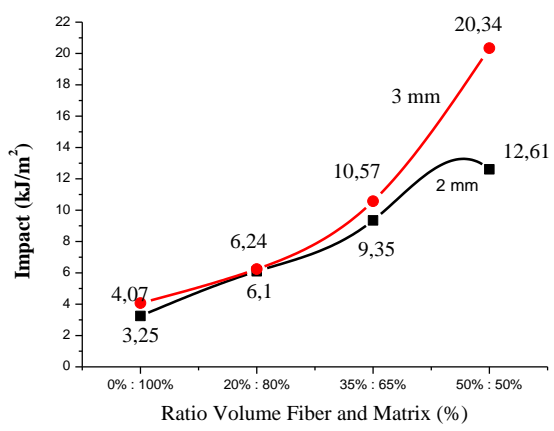

Figure 3. The impact of composite thickness of 2 mm and $3 \mathrm{~mm}$.

Figure 3. shows that the highest impact value is equal to $12.61 \mathrm{~kJ} / \mathrm{m}^{2}$ obtained at a ratio of $50 \%: 50 \%$, while the lowest are in the ratio of $0 \%: 100 \%$ which amounted to $3.25 \mathrm{~kJ} / \mathrm{m}^{2}$. The highest impact value of $20.34 \mathrm{~kJ} / \mathrm{m}^{2}$ obtained at a ratio of 50\%: $50 \%$, while the lowest are in the ratio of 0\%: $100 \%$ which amounted to $4.07 \mathrm{~kJ} / \mathrm{m}^{2}$. The composite with a thickness of $3 \mathrm{~mm}$ has the highest impact on all the fiber volume fraction compared with the composite having a thickness of $2 \mathrm{~mm}$. That is because the thickness of an object, the greater the energy required to break it. In addition to thickness, the resulting impact is also influenced by variations in the composition of the composite. Impact values increase with increasing fiber volume fraction. This is in accordance with the function of the fiber as a filler increases the stiffness and strength of the composites $[18,19]$. The amount of fiber that the more lead weight 
received by each of the smaller fibers. The amount of fiber that many also cause the matrix used had a greater influence of the fiber so that the composite is not prone to cracking.

\section{CONCLUSION}

Research by utilizing the Sansivieria Trifasciata as a filler composites produced some conclusions as follows:

1. The addition of fiber as a filler can affect the compressive strength and tensile strength of composites. Optimal composition for the resulting composite is 50\%: $50 \%$.

2. Composite thickness variation affects the compressive strength and tensile strength increased thickness of the composite the more powerful the less compressive, but the tensile strength increased. Reduction in compressive strength of composites is caused by the increase in the amount of force that is not big enough, when its thickness increases. This is because the nature of the fiber leaves which has a small and delicate forms.

3. Based on the analysis of compressive strength, tensile strength and impact can be concluded that the resulting composite material can be used as alternative to fiberglass because it has a compressive strength and tensile strength is greater, because on the composite compressive strength tests obtained for 128.63 MPa, while for fiberglass obtained at 36.2 $\mathrm{MPa}$. It means the mixing between Sansivieria Trifasciata's fiber as filler and epoxy resin as a matrix can produce stronger, thinner and cheaper than the manufacture material composite .

\section{Acknowledgments}

Thanks the Directorate General of Higher Education, Ministry of National Education Republic expecially for Bureau of Science Research, UNSOED for its support in oru research by its grant, namely RISET PEMULA.

\section{REFERENCES}

[1] Hugh D. Young., And Roger A. Freedman., Physics (University Physics Tenth Edition, 2000).

[2] Van Valck, Lawrence H., Elements of Materials Science and Engineering 6th Edition (Erlangga,Jakarta, 1989)

[3] Schaffer, James P., The Science and Design of Engineering Materials (McGraw-Hill, NJ, 1989).

[4] Indonesia National Standard, ISO 1811-2007, National Standardization Agency.

[5] Tata Sudira and Shinroku Saito., Knowledge of Engineering Materials. (PT Pertja. Jakarta, 2000).
[6] Jokosisworo, Sarjito., Effect of Cane Use of Fiber Skin For Upholstery In Polymer Composites With Matrix Yukalac Polyester Pull And Power Of 157 And Bend, 2009, Vol.30 Number 3 ISSN 08521697.

[7] Pramuko, I., Effect of Long-Fiber Composites Against Impact Strength With water hyacinth matrix Polyester, 2006, Vol 7.No 2. Muhammadiyah Surakarta University.

[8] Arfie Armelia E.I, Bambang K.H and M. Kusni., Pull strength analysis of laminated composite Bamboo Fiber Overlay and Wooven made by Manufacturing Method Hand Lay-Up, 2010, ISBN :978-602-97742-0-7.

[9] Hartanto, Ludi, Alkali Treatment and Study of Fiber Volume Fraction Of Strength Bending, Pull, and Impact Composite Berpenguat Polyester Fiber Hemp Bermatrik BQTN 157, Thesis, Faculty of Engineering, UMS, Surakarta, 2009.

[10] Giancoli, Douglas. C. Physics Fifth Edition. Erlangga.Jakarta, ,1998)

[11] Feynman,Richard.P., The Feynman Lectures on Physics Mainly Electromagnetism and matter (Addison-Wesley Publishing Company,Inc, 1963).

[12] Sarojo, Ganijanti Aby., Series Physics Mechanic (Salemba Teknika.Jakarta, 2002).

[13] ASTM. D 790 - 02 Standard test methods for flexural properties of unreinforced and reinforced plastics and electrical insulating material. Philadelphia, PA : American Society for Testing and Materials.

[14] D. William, Material Science and Engineering an Introduction (John Wiley \& Sons, Inc, 2007).

[15] Landel, R.F., Mechanical Properties of Polymers and Composites (2nd edition, Marcel Dekker, NY, 1994).

[16] Strong, A.B., Fundamentals of Composites: Materials, Methods, and Applications (Society of Manufacturing Engineers, Dearborn, MI, 1989).

[17] Hull, d and T.W. Clyne, An Introduction to Composite Materials, (2nd edition, Cambridge University Press, NY, 1996).

[18] Ashbee, K.H., Fundamental Principles of Fiber Reinforced Composites (2nd edition, Technomic Publishing Company, Lancaster, PA, 1993).

[19] Agarwal, B.D. and L.J. Broutman, Analysis and Performance of Fiber Composities (2nd edition, Wiley, NY, 1990). 